\section{CIENCIA Y ENSEÑANZA: UNA FAMILIA LIBERAL DE MANUALES*}

\author{
José Luis Peset \\ IH-CCHS-CSIC \\ Albasanz, 26-28. 28037 Madrid \\ joseluis.peset@cchs.csic.es
}

\section{SCIENCE AND EDUCATION: A LIBERAL FAMILY OF TEXTBOOKS}

\begin{abstract}
The teaching of Hygiene in Spain during the 19th Century follows the classical paths, coming from Hippocrates and Galen. The tradition of the sex res non naturales is pursued along the main textbooks of Francisco de Paula and Jacinto Montells y Nadal, putting their ideas in comparison with some other books consulted or translated during the period. Nevertheless, there were some innovations, as the introduction of modern Chemistry, or modern Physiology.
\end{abstract}

KEY WORDS: 19th Century; Hygiene; Chemistry; Physiology; Textbooks.

\section{Moderados y PRogresistas}

Al escuchar una reciente comunicación en el instituto Isabel la Católica a Natividad Araque y Carmen Colmenar' ${ }^{1}$, me saltó el apellido de un viejo conocido, el de Francisco Montells y Nadal, catedrático de Química y rector de la Universidad de Granada en el siglo XIX. Resulta interesante un personaje que, nacido en Barcelona a fines del mundo ilustrado, se instala en Granada, insertándose en el positivismo decimonónico, con algunos rasgos románticos. Personaje de primera importancia en la historia de la ciudad que lo acogió al empezar el reinado de Isabel II, también lo es en la historia de la educación y de la ciencia. En efecto, algunos manuales de la época estaban firmados con este apellido, con distinto nombre de pila, pero con este apellido. Ante esta llamada, mis primeros pasos fueron acudir al Palau y a la historia de la Universidad de Granada, que el químico escribió. En la edición que esta Universidad realizó en el año 2000 con motivo del centenario de Carlos V , encontramos un notable estudio preliminar de Cristina Viñes Millet (Viñes Millet, 2000). También ha sido editado por Manuel Fernández González, Ramón Gago Bohórquez y Cristina González Sevilla, un proyecto de este autor para unir por ferrocarril Granada con Córdoba y
RESUMEN: La enseñanza de la Higiene en España durante el siglo XIX siguió los caminos clásicos, procedentes de Hipócrates y Galeno. La tradición de las sex res non naturales es seguida a través de los principales manuales de Francisco de Paula y Jacinto Montells y Nadal, poniendo sus ideas en comparación con otros libros consultados o traducidos durante el período. Sin embargo, hubo algunas innovaciones, como la introducción de la química o la fisiología modernas.

PALABRAS CLAVE: Siglo XIX; Higiene; Química; Fisiología; Libros de Texto.

Málaga (Fernández González, Gago Bohórquez, González Sevilla, 1993)².

Nace Montells y Nadal el 22 de julio de 1813 en Barcelona en una familia liberal. Estudia en las Escuelas de la Lonja de la Real Junta de Comercio. Era una notable institución, surgida al fin del período ilustrado, para compensar las deficiencias que tenía la ciudad en educación. Suprimidas las universidades catalanas por el rey Felipe V, había puesto en pie la Universidad de Cervera. Aunque tenía ésta la enseñanza de medicina, carecía de muchas aulas científicas y técnicas, lo que se intentó paliar con las cátedras de la Junta de Comercio. Entre el profesorado destaca Francisco Carbonell y Bravo, en la cátedra de Química, maestro entre otros de Orfila y de José Roura, quien enseñó a Montells. También estudia éste en un colegio religioso, siendo su catolicismo sincero. Llega en 1833 a Granada, donde ha conseguido cátedra de Química en el Real Conservatorio de Artes, creado en 1824 a imitación francesa para patentes y enseñanza técnicas.

Señala Cristina Viñes Millet la visión de Montells sobre la decadencia del antiguo reino granadino, por las guerras -la del francés, las americanas y las carlistas-, las catás- 
trofes naturales y epidemias, la pérdida de la centralidad que tuvo la ciudad, que pierde instituciones como la Real Chancillería. También influian las malas comunicaciones, la decadencia de las artes y oficios tradicionales, así como del comercio, la agricultura y la industria. Él se preocupa por el desprecio de la ciencia y de la química, necesaria para las industrias de lanas e hilazas, abonos, papel, tintes, colores, pinturas, barnices, metales, porcelanas, cristales, sales y medicamentos. "Se consiguió además difundir entre la multitud unas ciencias que se miraron en su principio como diabólicas, creyendo algunos inocentes que sus profesores tenían misteriosos contratos con los espíritus ocultos." (Fernández González, Gago Bohórquez, González Sevilla, 1993, 25) No menos se preocupará tanto por minerales y materiales importantes, como por los caminos y las comunicaciones y la energía, así el gas y el carbón, que servirán para motores o alumbrado. El fin del antiguo régimen había sido un duro golpe para Granada, con dificultades para subirse al tren de la modernización capitalista. Parece que la minería estaba en auge, pero la ley nueva permitía la libertad de explotación y exportación, en lo que está en contra Montells (Fernández González, Gago Bohórquez, González Sevilla, 1993, xx-xxii; Peset, Garma, Pérez Garzón, 1978, 87-107).

Las soluciones para el profesor de Química son tanto politicas como educativas, ambas imbricadas. Y, por encima de todo, el empleo de la ciencia, que ilustrados y positivistas consideraban el mejor remedio para el atraso español. Las ideas progresistas - por lo tanto, propias de un seguidor del general Espartero- apoyaban la educación del pueblo. La educación popular debía ir desde las primeras letras, hasta llegar a las cátedras de aplicación. Se trataba de una enseñanza práctica, no sujeta a estudios ni títulos profesionales, queriendo ilustrar al pueblo, que debe conocer sus derechos y deberes, sin separarse del trabajo diario en el campo, el taller o la fábrica. También era idea progresista la reunión de todos los niveles de enseñanza, primaria, secundaria y superior. Su misma carrera desde primeras letras al rectorado de Granada, muestra esta visión de la enseñanza (Peset, Garma, Pérez Garzón, 1978, 2-45). Bachiller en Filosofía ya en Granada, luego lo es en Medicina, licenciado en Medicina y Ciencias, se interesa también por el Derecho. Es trasladado a la cátedra de Química general de la Facultad de Filosofía el 28 de septiembre de 1845. A la vez enseñó en la cátedra de aplicación dependiente de la Sociedad Económica de Amigos del País, así como en el Liceo granadino. Es socio corresponsal de la Academia de Historia Natural y Artes de Barcelona y de la Academia granadina de medicina y cirugía, poco después socio de mérito de la Económica de Granada ${ }^{3}$. Su pertenencia al Liceo artístico y literario, muestra su carácter romántico y liberal, es allí profesor, colabora en la revista La Alhambra, reuniendo literatura y modernización, pues se ocupa de saberes científicos útiles. Participa en la revista Manual Tecnológico con algunos alumnos, en donde escribe de tan variados temas como minería y mineralogía, agricultura e industria, biografías de sabios y descubrimientos cientificos. También escribió Un paseo científico por la provincia de Granada, al parecer con dos ediciones, pero que no se encuentra.

Esa extraordinaria actividad muestra bien los cambios que están acaeciendo en el terreno de la enseñanza. Los ministros de los reyes Carlos III y Carlos IV se habian ocupado de la enseñanza universitaria, iniciando la línea de actuación que seguirán los liberales, con Quintana a la cabeza. Se quería una universidad centralizada, uniforme y moderna. Unas instituciones y personajes nuevos controlarán desde Madrid la universidad, así el Ministerio y el director de Instrucción Pública. Se reforzará el profesorado y el claustro de catedráticos. Se dan planes de estudio modernos, con libros de texto al día, esa gran cantidad de manuales que, con origen en el siglo XVIII, inundarán el XIX y el $X X$. Serán los liberales los que se preocupen de los otros tramos de enseñanza, dando planes de estudio conjuntos y consiguiendo que los ayuntamientos se ocupen de la primaria, así como las diputaciones de la secundaria. "Dos objetivos son prioritarios: conseguir que todo el mundo sepa al menos leer y escribir, y que cualquier trabajador conozca los fundamentos de su oficio. Esto es más útil a la nación que el disponer de un gran número de titulados universitarios, mientras las clases inferiores permanecen en la ignorancia" (Fernández González, Gago Bohórquez, González Sevilla, 1993, xvi).

La universidad quedaría como último escalón y como torre vigía para controlar los tramos anteriores. Además, en ella va prosperando la enseñanza de las ciencias. De esas ciencias que tan difícil acomodo tenían en el pasado. Así la antigua Facultad Menor de Artes o Filosofía, se convierte en 1845 en la mayor de Filosofía y en 1857 en las dos mayores de Ciencias y Letras (Peset, Peset, 1974). Pero juntamente van apareciendo otras instituciones, que colaboran 
en estas tareas. En el siglo XVIII surgen las academias y las sociedades económicas de amigos del país, en el siglo XIX los liceos y los ateneos. Además, la prensa tiene ahora un papel notable en esta difusión del saber, así de los conocimientos científicos y técnicos. No es extraño encontrar a Francisco de Paula Montells y Nadal colaborando con estas instituciones. Aparte de las instituciones nombradas, en muchas revistas, tanto culturales como políticas, estuvo como colaborador o director.

Su actuación en la universidad tiene gran interés. Asciende desde los primeros escalones, por traslado a la cátedra de Química de la Facultad de Filosofía, hasta llegar a rector. Sucede en el momento en que llega al poder el granadino Narváez y se promulga el Plan Pidal de 1845. Éste suprime las cátedras de aplicación de los conservatorios de artes y crea la Facultad de Filosofía y se eliminará la de Teología. Será secretario de Facultad y luego su decano en 1851, y con Moyano en la de Ciencias. Considera bueno el plan de estudios de 1845 por las instalaciones que propone (gabinetes, museos, laboratorios, jardines, bibliotecas), por el apoyo al profesor, al rector y al claustro de catedráticos. En 1846 pronuncia el discurso inaugural de la Universidad inspirado en el de Lorenzo Arrazola -decano de la Facultad de Derecho- en Madrid en el año anterior. Se ocupará de montar los edificios, gabinetes, museos y laboratorios; arregla el archivo y la biblioteca; visita colegios e institutos del distrito. Siempre aprovecha las ocasiones para subir un escalón y mejorar la Universidad. Pronuncia el discurso inaugural en 1868, y fue rector entre 1868-1872, pero pronto está disconforme con las novedades, por lo que presenta observaciones sobre las reformas progresistas. Se separa de éstos, y apuesta por el control y la centralización. Antes se debía imitar a los franceses, nos dice, pero ahora se mira más al norte; también quiere exámenes y calificaciones, mantener el orden académico, no hay que extrañarse en quien también fue vocal en el consejo de disciplina interna. Junto a la defensa del profesorado considera también necesario el control desde el decanato, el rectorado y el ministerio. Defiende pues la universidad que ha modelado, en la que ha enseñado y ascendido, la universidad de Moyano que Cánovas restaurará. No olvidemos tampoco que en Madrid -y también en Granada- comienzan y/o se intensifican en el Sexenio los movimientos estudiantiles.

En Francisco de Paula, Montells y Nadal se juntan aspectos pragmáticos con otros románticos. Es un personaje que supo aprovechar las coyunturas políticas para su carrera, sin embargo, sin mendigar, como él mismo nos dice. También es el joven patriota, que encuadrado en la milicia nacional defiende el partido progresista (Pérez Garzón, 1978), amigo de Madoz y entusiasta de Espartero. Defiende siempre las comunicaciones y el progreso económico, la cultura y la educación, los centros gratuitos de primaria dependientes del ayuntamiento, la mejora del plan de estudios en la universidad. "Todas ellas [posturas] vinculadas en última instancia al presente y al futuro de su país, cuya mejora constituyó un eje central en su pensamiento y en la mayor parte de las actuaciones que pudo llevar a cabo a lo largo de su existencia" (Viñes Millet, 2000, viii). 0 bien, es también el médico dispuesto a atender a la población en las epidemias de cólera. Los años de la Gloriosa fueron para él difíciles. A los trágicos dolores por la muerte de la esposa, se une la ruptura del progresismo, los debates en la prensa política, en El Triunfo Granadino y en El Progreso. Tras la muerte de Prim, el partido se escinde entre Ruiz Zorrilla y Sagasta, con éste queda Montells.

Son también los años en que escribe la historia de la Universidad de Granada, obra que le ha dado la mayor fama. Al parecer había sido solicitada años atrás en 1867, cuando era ministro Orovio, pero la comisión encargada apenas avanza. De nuevo fue solicitada en 1869, y es cuando se hace cargo Montells de la redacción. Tenía a su favor su buen conocimiento de la universidad y sus instituciones, así como de sus archivos, en contra las nuevas ideas de libertad y descentralización, que no compartía por entero. Empieza a aparecer en 1870 por entregas, que abaratan los costos; tarda cinco años en concluirla, formando el magnífico libro que hoy conocemos gracias a la alta tirada. Se insiste en sus páginas en el apoyo al Estado, contra la indolencia de los reyes y de la Iglesia, considera buena la expulsión de los jesuitas, que permitió el traslado de la Universidad, pues como en general sucedió, las universidades consiguieron aprovechar los edificios, libros y materiales de la orden docente.

Tanto en su redacción, como en otros escritos, se mostró contrario a muchas de las nuevas ideas. El progresista de corazón, era en su mente un moderado. Problemas diversos tuvo en su rectorado, al parecer no quería camarillas universitarias, vieja lacra heredada, y pretendía controlar los gastos y mejorar los centros y edificios, el paraninfo, y recuperar la casa comunidad de la orden de Jesús en ma- 
nos del ejército. Quiso también controlar las cuentas y las obras en la Facultad de Medicina (que se había instalado junto al hospital de San Juan de Dios), y surgen motines de alumnos médicos (en la calle y en la prensa) por su informe de 1872 contra la libertad de enseñanza, luego se alzan en su contra antiguos correligionarios. Choca por su interés en el orden, por enfrentarse con la excesiva libertad en el terreno de la docencia y la economía. No le gusta el caótico desarrollo capitalista de la época, que afectaba a terrenos muy queridos para él, como el docente y el minero. Ese año cesa y en 1877 logra la jubilación, se traslada a Barcelona, su ciudad natal, donde muere en 1893. Había escrito en 1883-1884 su obra postrera Dios, la Naturaleza y la Humanidad, en la que quiere conciliar fe y saber, mostrándose como un férreo antidarwinista. Su romanticismo aunaba fe en el progreso y en la religión católica.

\section{Los manuales de texto}

Desde luego, la redacción de manuales era tarea importante. Hasta el siglo XVIII la universidad seguía utilizando los viejos tomos en latín de los clásicos. A partir de mediados de ese siglo, se quieren libros cortos y sencillos, que estén al día y en castellano. La ciencia, que en épocas anteriores tardaba décadas o siglos en llegar, se introduce ahora con rapidez; las novedades tardan pocos años en llegar. Los libros se redactan de acuerdo con criterios pedagógicos y científicos, siguiendo las novedades que aparecen en estos terrenos. Además se adaptan a unos planes, a unas asignaturas y a unos años de estudio, que pronto impondrá el Ministerio. Los autores suelen ser científicos más o menos conocidos; algunos se especializan en esta tarea y escriben abundantes libros, que van adaptando en sucesivas ediciones a las novedades científicas, pedagógicas y ministeriales. Se dotan de un estilo sencillo, que facilite el aprendizaje y la memorización de sus contenidos. El examen es el objetivo final de todas estas tareas.

\section{La nueva Química}

La Química, antes de convertirse en ciencia pura, tiene un importante pasado aplicado. Su origen viene o bien de la alquimia, o bien de actividades prácticas como la medicina, la farmacia, la minería o la artesanía. Podía ser estudiada para buscar la piedra filosofal, un remedio eficaz o un tinte 0 un proceso minero o metalúrgico. Con Lavoisier se crea la Química moderna (Mieli, 1948), se actualiza la idea de que la materia está formada por elementos, se les da nombres, que pueden ser clásicos, por sus propiedades o por su origen (descubridor o lugar de descubrimiento), se aislan y estudian, se ven sus caracteres y reacciones. Se trata de una química más cercana a los procesos de análisis y que conoce mejor la materia inorgánica. El futuro se dirigirá hacia los problemas de la síntesis química y se ocupará de la materia orgánica, iniciado con la urea. Poco a poco la Química como saber teórico adquirirá mayor importancia, pasando de las escuelas técnicas o de las facultades médicas y colegios de cirugía a las facultades de ciencias. Así se entiende el camino profesional seguido por Montells: cátedras para artesanos, estudios de ampliación, cursos para médicos o la colocación final en la Facultad de Ciencias.

En 1845 se publica el tomo primero del Tratado de Química de J. J. Berzelius, a partir de la cuarta edición alemana de 1838, traducida al francés por B. Valerius, y ésta al casteIlano por Rafael Sáez y Palacios y Carlos Ferrari y Scardini. Ambos son farmacéuticos de los hospitales generales de Madrid, el primero también profesor de la Facultad de Ciencias médicas de la Corte. Muestra bien el interés de la farmacia y la medicina por la nueva química (Bertomeu Sánchez, García Belmar, 2000). No tiene muchas indicaciones médicas, pero tiene una importante referencia al papel del cloro, que si bien es normal en la época del cólera, sin duda es clave de la relación con los saberes médicos.

En un prólogo a la obra, que firma en 1835 en Estocolmo, afirma que con su libro sirve a la inteligencia y a la memoria, más que al orden sistemático. Se plantea pues, que está escribiendo para alumnos, estudiantes que tienen intereses sabios o profesionales. "También he procurado hacer la lectura de mi libro tan agradable como lo permite la naturaleza de los objetos sobre los que versa" (Berzelius, 1845, vi-x). Una de sus dudas principales está en el orden de exposición entre cuerpos simples con combinaciones, o primero los cuerpos y luego las combinaciones. Quiere fomentar la curiosidad para facilitar el estudio, para ello empezará por los cuerpos más difundidos e importantes. Pasan por sus páginas los átomos, la cristalografía, la afinidad, las proporciones químicas, tal vez sigue a Dalton (Solís, Sellés, 2005, 504-507 y 876-881). Inicia con la luz, el calórico, las fuerzas eléctricas (frotación, pila de Volta, 
nubes) y las magnéticas (electro-magnetismo de Ampère y Arago, aguja imantada). Si estas páginas suponen una necesaria incursión en la Física, luego divide la Química en inorgánica y orgánica, y aquélla en metaloides y metales. Los elementos griegos son compuestos, en su época se buscan cuerpos simples. Nos presenta sus ideas sobre el aire, el agua, la atmósfera, seguirá con oxácidos e hidrácidos, en adelante irá completando las distintas partes de la Química. Le importa más la presentación de las principales teorias que su propia clasificación. Así nos habla de las combinaciones, las proporciones químicas, la teoría electroquímica. Todavía no están estas ideas por entero claras, por lo que no cuantifica la composición de los cuerpos. Luego prosigue con la Química vegetal, la animal, en fin, se ocupa de los términos y los instrumentos químicos y de los procesos de los análisis químicos. No es la historia parte de la Química, pero considera importante los distintos descubridores (herencia del siglo XVIII, en que comienza la disputa por aislar nuevos elementos) y también la evolución de las principales teorías. No admite el origen del término química del griego, sino del árabe alquimia, sin duda conoce la realidad del saber árabe y la importancia de esta práctica medieval. Para unos el calórico es lo mismo que la luz, según la mayor o menor velocidad, para otros vibraciones que se transmiten a nuestros órganos.

El más notable libro que dedica Montells y Nadal a la enseñanza es su Curso de Física experimental y nociones de Química. Se trata de una obra encaminada a seguir los pasos de la reforma de la enseñanza, declara con orgullo que el Consejo Real de Instrucción Pública la ha declarado libro de texto. Está dedicada a Alejandro Oliván, senador y académico de ciencias. Incluye un pequeño formulario en que el catedrático asegura que el alumno que lo ha comprado está matriculado, e indica incluso el número de esta matrícula. En la "Advertencia de la primera edición" -firmada en 1848- señala que lo ha escrito siguiendo los programas oficiales de 1846 . Son una parte de las muchas mejoras que se han impuesto en la enseñanza, en la universidad que ahora cuenta con gabinetes y laboratorios y en los institutos con sus aparatos y máquinas. Para la emprendida "regeneración social" son precisos manuales "donde el autor no haciendo alarde de pomposas teorias ni de grande sublimidad, presente la ciencia con el atractivo de la naturaleza, haciendo uso solamente de aquellas teorías y cálculos que pueden ser bien comprendidos por los alumnos". Los alumnos de quinto de Filosofía seguirán la letra redonda, los de Ampliación también la cursiva. Numera los apartados para facilitar la clase, la memorización y el examen. También recurre a publicaciones separadas. Las lecciones de Química están extractadas de su curso elemental. Ha consultado los más eminentes profesores (autores), periódicos (revistas) y diccionarios.

En el "Prólogo de la segunda edición" nos dice que algunos compañeros lo han animado a "que siga el plan de reforma que nos emancipe de la tutela extranjera y contribuya con algunos materiales al edificio científico del siglo XIX". No puede por falta de fuerzas y teme el desdén de algunos porque "saldría del oscuro rincón de una provincia". También nos dice que no incluye su biografia, hecha por alumnos, porque los "sucesos de mi juventud" sólo son muestra de un "corazón entusiasmado y de un cerebro excitado por ideas halagüeñas". Se unen la afición al "estudio de las ciencias naturales" con "los desengaños que he sufrido en una época en que solo impera la política y los que toman en ella la iniciativa". Pide ayuda a quienes puedan informarle de novedades, pues "arrinconado en una provincia, vivo oscurecido y fuera de los círculos de acción". Es necesario "ilustrar al pueblo" para sus "imprescindibles necesidades" para que "la educación cunda hasta las clases menesterosas, y que tienda a crear capitales productivos" (F. Montells, 1854, vii-ix y xi-xv).

En esta edición sigue el programa oficial de 1850, que está más ceñido y quita las ampliaciones. Presenta un largo apartado de historia de la Física, se preocupa de los descubridores de elementos, de las etimologías y las nomenclaturas, añade temas importantes como el tiempo y el espacio, las fuentes de calor, el equivalente químico, la teoría y la escala electroquímica. En Física incluye las propiedades de los cuerpos (extensión, porosidad, compresibilidad, inercia), la mecánica de sólidos y fluidos, las acciones moleculares, el calor, la luz, el magnetismo y la electricidad. En Química los cuerpos simples, la nomenclatura ${ }^{4}$, la cristalización, la teoría electro-química, la teoría atomística, la combinación, el análisis y la síntesis, etc.; los cuerpos metaloides y sus combinaciones, los óxidos y ácidos metaloides, los metales y sus compuestos. La galvanoplastia. Al final se incluyen grabados con esquemas e instrumentos de física y de química.

En 1846 publica sus Nociones elementales de Química como libro de texto para alumnos de quinto año de Fi- 
Iosofía (Fernández González, Gago Bohórquez, González Sevilla, 1993, xxvii-xxxiii) ${ }^{5}$. Es un resumen de su anterior obra extensa, sin duda de estudio árido. Lo dedica a los gobernantes, en la tarea de mejora que están realizando. Se trata de un catálogo de "cuerpos" "inorgánicos" y "organizados", con su descubridor y sus propiedades. Reconoce los méritos de Del Río y de Fausto Elhuyar, olvidando a Juan José. Se ocupa con cierto cuidado de la nomenclatura, que discute a Berzelius y a Guyton de Morveau. Conoce bien al químico sueco y detalla su teoría atomística. Parece seguir el mismo orden de éste, si bien la concisión y el acúmulo de datos convierte a este manual en un aburrido compendio.

\section{La salud humana}

En el siglo XIX la Higiene consigue logros importantes. Hasta el siglo XVIII es una de las disciplinas que se mantienen más fieles a las doctrinas hipocráticas. Los médicos griegos clásicos establecieron la que ha sido la más importante norma de la medicina, el principio de no dañar al enfermo, el primum non nocere (Laín, 1970). Por ello establecían unas pautas progresivas en la terapéutica, desde los comportamientos más inocuos a los más agresivos. En primer lugar, de acuerdo con estos criterios, se usaba la dieta, luego la droga y por último el hierro. La higiene, la farmacología y la cirugía tienen aqui su origen. La dieta era una regulación completa de la vida del enfermo, que en pacientes ricos era casi molesta y abusiva. Platón se burla de esos médicos que acogotaban a sus pacientes con sus remedios, como ese médico por Osuna que atemoriza a Sancho Panza en Barataria. La dieta se prescribía de acuerdo a unas normas hipocráticas que la tradición galénica encerrará en las Ilamadas sex res non naturales.

En el estudio de la Fisiología humana se distinguían éstas de las res naturales, y de las contranaturales. Las naturales eran los componentes normales del cuerpo humano, humores, partes sólidas, órganos y miembros; las contranaturales las que producian la enfermedad, un rayo, un veneno o un traumatismo. Las no naturales eran las que unas veces estaban en el cuerpo y otras no, las que unas veces ocasionaban enfermedades y otras no. Se refería a comida y bebida, trabajo y reposo, vivienda y ambiente, pasiones y sexualidad..., éstas eran reguladas por la dieta, que se convertirá en la higiene privada. Eran unas normas que cumplian las reglas clásicas de respeto por la natura- leza, y atenerse a sus leyes era el principio a seguir. El médico es un servidor de la naturaleza (Laín, 1964; Vigarello, 1985). Pero las enfermedades epidémicas se escapaban de estas normas (Peset, 1993a). Eran violentas, repentinas, con cursos azarosos. La lucha contra ellas fue muy precoz, destacando las medidas en el cambio al período moderno de algunas ciudades italianas, que establecen lazaretos, o bien limpiezas y aislamientos. Se empieza así la higiene pública, que comienza con la benevolencia de la policía ilustrada, pero que continúa al establecerse el moderno estado burgués. Control de las enfermedades, sobre todo de las epidémicas, con la colaboración eficaz del derecho y de la ciencia, con apoyo del poder. Así la Química fue esencial en la prevención y lucha contra las enfermedades.

En el libro de Montells y Nadal Idea sucinta fisico-química sobre la infección y desinfección... (F. Montells, 1834) se plantea la protección, sin duda ante el cólera, por medio de productos químicos. Productos en general con características organolépticas muy marcadas (olor, sabor, tacto), que por observaciones se sabía que tenían propiedades para evitar la corrupción, considerada peligrosa causa de enfermedades, incluso epidémicas. Era una práctica antigua, por ejemplo el vinagre ante la peste. Otros productos, como la salmuera, compartían con el vinagre la propiedad de conservar los productos orgánicos. Además, la sal, su componente, era un producto sagrado y venerado desde siempre. Se empleaba en ritos sagrados, así en el bautismo cristiano, era un producto estanco y caro, que constituia principal ingreso de muchos poderosos, y excepcional producto mineral de la alimentación humana. Pero ahora la nueva química de Lavoisier había permitido conocer mejor los productos que se empleaban, tanto sus componentes y reacciones como sus propiedades.

Los ácidos -así el clorhídrico y el acético- eran muy apreciados, unos para la preservación de alimentos y productos corruptibles, otros para la desinfección. El ácido muriático es empleado en la fiebre amarilla por influjo de Guyton de Morveau. Se llama ácido muriático por la palabra latina muria-ae, que significa salmuera. No es extraño que veamos a Montells discutir sobre el uso de diversos derivados del cloro ante el cólera (Peset, Peset, 1972) ${ }^{6}$. Aunque no se sabía todavía, el bacilo del cólera, como otros muchos, se transmite a través del agua. Todavía hoy es el cloro el encargado de limpiar las aguas y 
evitar muchas enfermedades y las infecciones que entran por el aparato digestivo.

El cloro en agua también blanquea los tejidos para la industria, en lo que está de acuerdo Berzelius: "Esta propiedad del agua saturada de cloro -afirma- fue descubierta por Berthollet, que aplicó en grande al blanqueo del lino y del algodón [...]". El cloro unido al agua, no solamente destruye los colores de origen orgánico, sino también las emanaciones olorosas de los animales y vegetales enfermos o muertos: del mismo modo que los miasmas, tanto los que se propagan por el intermedio del aire (miasmas propiamente dichos), como los que obran solamente por un contacto inmediato (principios contagiosos). He aquí la razón por qué se hace uso del agua de cloro para lavar las telas y otros efectos en que se sospecha la existencia de gérmenes de contagio o infección, y también por la que se hace desprender cloro en las habitaciones de los enfermos, especialmente en las enfermedades contagiosas. Se usa generalmente con este objeto en los hospitales: "Debo advertir que el desprendimiento de cloro que se produce en la habitación de los enfermos no ha de ser tal que pueda perjudicar la respiración" (Berzelius, 1845, 209-210). Empezó el empleo del cloro en 1769 con Guyton de Morveau, quien usó gases ácidos para eliminar olores de la catedral del Dijon que producian los cadáveres enterrados en sus bóvedas. Durante un tiempo se olvida, pero lo resucita un médico inglés llamado Smith en tiempos de epidemias en hospitales. En la fecha -se nos afirma- se usa el cloro gaseoso con éxito.

Pero la Higiene de los manuales se mantenía en los esquemas galénicos, así en Francia podemos consultar el libro de los doctores en medicina de la Facultad de París Buchez y Trélat de 1825 (Buchez, Trélat, 1825). Alli se mantienen los mismos apartados de la tradición galénica. Así nos presentan una división en circumfusa, applicata, ingesta, excreta, percepta, animi pathemata, gesta. También temperamentos y hábitos, edades y géneros, trabajo y herencia. Lo mismo se encuentra en la obra Elementos de Higiene privada de Pedro Felipe Monlau (Monlau, 1846). Así va estudiando Atmosferología, Cosmetología, Bromatología, Gimnástica, Perceptología. Añade una Higiene privada especial con clima y habitación, raza, edad, sexo y temperamento, constitución, hábitos, profesión y estado. En este se refiere a estados de civilización, paz, libertad, riqueza, poder, matrimonio, claustral, rural...

Si en el libro de Buchez y Trélat se mantiene la división en los apartados galénicos, un nuevo paso se da en el libro de 1827 de Carlos Londe Nuevos elementos de Higiene privada y pública, varias veces traducido a lo largo de muchos años. Así por un profesor clínico de la Facultad de Medicina de Madrid, quien explica los motivos de su traducción tardía, la necesidad de tratados de Higiene, el esfuerzo del autor por ponerse al día, lo que incluye muchas novedades. Pero insiste en justificar la traducción de un libro que se aparta de otros de la misma materia. En efecto, se está produciendo un cambio de la higiene hacia una orientación fisiológica, como nos dice el autor al afirmar que se intenta "dirigir los órganos en el ejercicio de sus funciones". Sin duda, se constata el esfuerzo por estar al día que Londe hace en fisiología, de ahí que aparezcan primero los nombres de Gall, Adelon y Broussais y en posteriores ediciones Dumas y Magendie, Müller y Bernard. Pero el traductor Rogelio Casas nos quiere convencer de que la higiene se

\begin{tabular}{|l|c|c|}
\hline \multicolumn{1}{|c|}{ DIVISIÓN FISIOLÓGICA } & DIVISIÓN DE GALENO & DIVISIÓN MODERNA \\
\cline { 1 - 1 } De los órganos de los sentidos & Percepta & Perceptología \\
\cline { 1 - 3 } Del encéfalo & Acta. Gesta & Gimnástica \\
\hline Del aparato locomotor & Ingesta & Bromatología \\
\hline Del aparato digestivo & Circunfusa & Atmosferología \\
\hline \multirow{2}{*}{ Del aparato respiratorio } & Aplicata & Cosmetología \\
\cline { 1 - 3 }
\end{tabular}


mantiene en sus cauces tradicionales, y así nos lo prueba con una comparación entre las divisiones antiguas y modernas (Londe, 1829; Londe, 1871, i y v-vi).

En 1874 aparece la tercera edición de los Elementos de Fisiología é Higiene de Jacinto Montells y Nadal, doctor en farmacia, catedrático de nociones de Historia Natural en el instituto de la Universidad de Sevilla (Carrillo Linares, 1998; Trigueros Gordillo, 1998). Firma ejemplares como autor propietario, lo que demuestra el beneficio comercial de estas publicaciones. La unión de Fisiología e Higiene en el título nos habla de que se encuentra en la misma senda de "fisiologización" de esas sex res non naturales. En la primera disciplina nos interesa insistir en la presentación del temperamento, la constitución, los hábitos, las edades... en que nos muestra el desarrollo humano. Sin duda es una adaptación a la fisiología y por tanto a la edad, al género, a la constitución y al temperamento. Los temperamentos que considera son nervioso, sanguíneo-vascular, bilioso y linfático, lo "que indica la preponderancia de alguno de los cuatro fluidos más importantes de la economía animal"7. Más o menos sigue siendo herencia de las doctrinas galénicas, que suponía que eran los humores del cuerpo la base de la constitución y el temperamento.

En la parte del libro consagrada a la Higiene, la sección primera se ocupa de la Atmosferología, desde el aire a la vivienda. También se interesa brevemente por las epidemias, con presentación del concepto de profilaxis, y de algunas instituciones que vienen de la higiene tradicional, como los lazaretos y los cordones sanitarios. Por aquella época, aterrada la población ante el cólera y su extensión, se dudaba de estos sistemas tradicionales de protección. Distingue entre infección "la acción tóxica del aire contaminado" -el "aire miasmático" de la tradición clásica-, del contagio entre individuos. La segunda sección es la Cosmetología (vestidos y limpieza), la tercera la Bromatología (comidas y bebidas), la cuarta la Gimnasia, la quinta la Perceptología. Nos habla aquí de las sensaciones internas y externas, y de las orgánicas.

Más o menos sigue el esquema de las sex res non naturales, pues ha hablado de aire y habitación, ingesta, ejercicio, faltan algunas consideraciones sobre las pasiones. De ellas se ocupa cuando expone las necesidades sociales e intelectuales del ser humano. Las sociales suponen el "trato mutuo de los hombres constituidos en sociedad", las intelectuales el talento y las pasiones. Afirma que "los individuos dotados de gran talento, tienen muchas veces algún defecto corporal", pueden ser débiles y deformes, los gordos son más tontos. También arremete contra las pasiones, como amor, ambición, avaricia, juego..., e insiste en el exceso en el estudio, que es peligroso. Más tarde dirá que viven poco los que se dedican a trabajos intelectuales, aunque se dice que Galeno vivió 140 años. Retoma las ideas románticas sobre el hombre de genio, pero más bien las higienistas del suizo Tissot -que tuvo varias traducciones- en su libro sobre las enfermedades de los hombres de letras. Es una tradición clásica que viene de Grecia, y pasa por el humanismo italiano, la cual señala que los estudiosos -y artistas- sufren más la enfermedad, por sus caracteres o por sus esfuerzos. Sería un fanatismo dirigido a las ciencias, como hay otros hacia la religión, la patria, esa nostalgia es una melancolía. ¿La sentirian en Andalucía los Montells y Nadal hacia Cataluña?

En fin, se ocupa de las circunstancias favorables a la salud (J. Montells, 1874, 138, 188-193 y 260-271). Convienen padres sanos y robustos, entra así en el terreno de la herencia. También interesa el parto y el crecimiento, la ocupación y el trabajo. No es bueno para el proletario el trabajo sobre todo si es precoz, pues hay industrias perjudiciales. Son buenos el comercio y el ejército. Tampoco son saludables para los ricos la educación precoz, los malos hábitos, la "vida borrascosa", los placeres. Es importante la educación, la ocupación, el ejercicio, la constitución física, que distingue entre la mujer y el hombre. Sobre todo el matrimonio feliz. Sin duda, aqui de nuevo se enlaza con las sex res non naturales. Por un lado, por las pasiones, pues su control era necesario, también para la psiquiatría y la medicina legal. Se ocupará Pedro Felipe Monlau de estos temas en su Higiene del matrimonio. Por otro, en las sex res estaban las excretas y las relaciones sexuales. La eliminación del semen era tema importante, incluso curación de males, en la tradición del escrito Problemas, atribuido a Aristóteles o Teofrasto. Pero la educación católica exigía el buen comportamiento marital, que eliminaba problemas psíquicos, infecciosos y también económicos y sociales. Sin duda, recoge la tradición de la higiene acorde con la naturaleza, esa idea del médico hipocrático que se considera su servidor. Las normas de la vida sana -en general agrícola, con desconfianza hacia las urbanas, herencia de Rousseau y Tissot- son las que restituyen al ser humano al estilo de vida tradicional. 
* Programa CEIMES "Ciencia y educación en los institutos históricos madrileños de enseñanza secundaria a través de su patrimonio cultural" (Comunidad de Madrid, S2007/ HUM0512).

1 Artículo de Natividad Araque Hontangas y Carmen Colmenar Orzaes, recogido en este mismo número.

2 Es memoria premiada por la Real Sociedad de Amigos del País de Granada en 1853. Tratará este tema en la Sociedad Económica en 1855, y en el Liceo en 1867.

3 Es vocal de su Junta particular, secretario de la Sección de industria y artes, presidente de la de manufacturas y oficios, censor... presenta trabajos sobre cloritos y ferrocarril, la representa en el Congreso de agricultura de Madrid, la reina lo nombra vocal de la Junta general de agricultura.

4 Duda de hidrácidos, cambios en nomenclatura en combinaciones binarias (óxido, clórido, súlfido). Cita para nomenclatura a Berzelius, Lavoisier, Fourcroy, Guyton de Morveau, Davy, Dumas y Berthollet en pp. 398-399, también Proust en p. 419. En Nomenclatura Química arreglada a los conocimientos modernos hay distancia de la nomenclatura de Berzelius.

5 Cita al Gobierno en p. 6, a Del Río y Elhuyar en p. 43, a Berzelius y Guyton de Morveau en p. 129 y quizá en 138.

6 En otros lugares le interesa el agua oxigenada.

7 Cita a Huffeland en p. 268. Se interesó también por la Historia Natural y la Agricultura, llegando a director

Recibido: 1 de marzo de 2010 Aceptado: 30 de junio de 2010
Báguena Cervellera, M. ${ }^{a}$ José (1994): "La higiene y la salud pública en el marco universitario español", Rev. Sanit. Hig. Púb., 68, pp. 91-96.

Bertomeu Sánchez, José Ramón y Antonio García Belmar (2000): "Los libros de texto de química destinados a estudiantes de medicina y cirugía en España (1788-1845)", Dynamis, 20, pp. 457-489.

Berzelius, J. J. (1845): Tratado de química, t. 1, Madrid, Imprenta y librería de D. Ignacio Boix.

Buchez y Trélat (1825): Précis elémentaire d'hygiène, Paris, Chez Raymond, Éditeur de la Bibliothèque du XIXe Siècle.

Carrillo Linares, Alberto (1998): "La instrucción sanitaria del clero. El caso del Seminario Conciliar de Sevilla en torno a la crisis de 1898", Dynamis, 18, 1998, pp. 251-284.

Fernández González, Manuel; Gago Bohórquez, Ramón y Cristina González Sevilla (1993): "Estudio preliminar D. Francisco de Paula Montells y Nadal (1813-1893)", en Francisco de Paula Montells y Nadal, Proyecto para la ejecución de un ferro-carril, que desde Granada vaya á empalmar con el que se está ejecutando de Málaga a Córdoba, Edición facsímil de la hecha en Granada, Imprenta de D. Francisco Ventura y Sabatel, 1854, Granada, Universidad de Granada, pp. vii-xxv.

González de Pablo, Ángel (1995): "Sobre la configuración del modelo de pensamiento de la higiene actual: el caso español", Dynamis, 15, pp. 267-299.

Laín Entralgo, Pedro (1964): La relación médico-enfermo, Madrid, Revista de Occidente.

Laín Entralgo, Pedro (1970): La medicina hipocrática, Madrid, Revista de 0ccidente. 
Londe, Carlos (1829): Nuevos elementos de higiene, 2 v., Madrid, Imprenta que fue de Fuentenebro, Imprenta de Repullés.

Londe, Carlos (1871): Nuevos elementos de higiene privada y pública, t. I, 3. ${ }^{\mathrm{a}}$ ed. española, Madrid, Librería de Pablo Calleja y Compañía, Editores, trad. Rogelio Casas de Bautista.

Metzger, Hélène (1969): Les doctrines chimiques en France du début $d u X V I I^{e} \dot{a}$ la fin du XVIIle Siècle, Nouveau tirage, Paris, Librairie Scientifique et Technique Albert Blanchard.

Mieli, Aldo (1948): Lavoisier y la formación de la teoría química moderna, 2. ${ }^{\text {a ed., }}$ Buenos Aires, Cía. Editora EspasaCalpe Argentina.

Monlau, Pedro Felipe (1846): Elementos de higiene privada, Barcelona, Imprenta de D. Pablo Riera.

Montells y Nadal, Francisco de Paula (1834): Idea sucinta físico-química sobre la infección y desinfección acompañada de la fabricación y propiedades generales de los cloritos, impropiamente llamados cloruros, Granada, Imp. Viuda de Moreno, Hijos y Cía.

Montells y Nadal, Francisco de Paula (1837): Nomenclatura Química arreglada a los conocimientos modernos, Granada, Imp. Viuda de Moreno, Hijos y Cía.

Montells y Nadal, Francisco de Paula (1846): Nociones elementales de química (...) Obra destinada para que sirva de testo á los alumnos del quinto año de filosofia, Granada, Imp. de Benavides.
Montells y Nadal, Francisco de Paula (1849): Compendio de Física experimental y algunas nociones de Química arreglado al programa oficial, y según los últimos descubrimientos y teorías de ambas ciencias, Granada, Imp. de Benavides.

Montells y Nadal, Francisco de Paula (1853): El Tío Pedro o el sabio de la aldea, Madrid, Imp. El Preceptor.

Montells y Nadal, Francisco de Paula (1854): Curso de física experimental y nociones de química, 2. ${ }^{\text {a }}$ ed., Granada, Imprenta de los Señores Astudillo y Garrido.

Montells y Nadal, Francisco de Paula (1883-1884): Dios, la Naturaleza y la Humanidad, 2 vols., Barcelona, Imp. Riera.

Montells y Nadal, Jacinto (1874): Elementos de fisiología é higiene, 3. a ed., Sevilla, Imprenta y Litografía de C. Santigosa, Hijo.

Pérez Garzón, Juan Sisinio (1978): Milicia nacional y revolución burguesa, Madrid, CSIC.

Peset, José Luis (1993a): "On the History of Medical Causality", in Corinna DeskeIkamp-Hayes and Mary Ann Gardell Cutter (Eds.), Science, Technology, and the Art of Medicine, Dordrecht Boston London, Kluwer Academic Publishers, pp. 57-74.

Peset, José Luis (1993b): Las heridas de la ciencia, Valladolid, Junta de Castilla y León.
Peset, José Luis (1999): Genio y desorden, Valladolid, Cuatro Ediciones.

Peset, José Luis; Garma, Santiago y Juan Sisinio Pérez Garzón (1978): Ciencias y enseñanza en la revolución burguesa, Madrid, Siglo Veintiuno de España Editores.

Peset, Mariano y José Luis (1972): Muerte en España, Madrid, Seminarios y Ediciones.

Peset, Mariano y José Luis (1974): La Universidad española (siglos XVIII y XIX), Madrid, Taurus.

Solis, Carlos y Manuel Sellés (2005): Historia de la ciencia, Pozuelo de Alarcón, Madrid, Editorial Espasa-Calpe.

Tissot (1775): De la santé des gens de lettres, Lausanne, Chez Franç. Grasset \&t Comp., Lyon, Chez Benoit Duplain.

Trigueros Gordillo, Guadalupe (1998): La Universidad de Sevilla durante el Sexenio revolucionario, Sevilla, Universidad.

Vigarello, Georges (1985): Le propre et le sale. L'hygiène du corps depuis le Moyen Age, Paris, Éditions du Seuil.

Viñes Millet, Cristina (2000): "Estudio preliminar", en Francisco de Paula Montells y Nadal, Historia del origen y fundación de la Universidad de Granada, Granada, Editorial de la Universidad de Granada, pp. v-cxi. Facsímil de la edición original de Granada, Imprenta de D. Indalecio Ventura, 1870, por orden del Ministerio. 